\title{
Ensino de arte mediado pela criação e uso de software audiovisual
}

\author{
Alexandre G. Q. Rangel
}

\section{Resumo}

Este artigo apresenta um estudo sobre o uso de obras de arte abertas em ambientes de arte-educação, com foco nos processos de capacitação e colaboração interdisciplinar. As experiências aqui relatadas apontam para um caminho de empoderamento por meio do desenvolvimento e adaptação de programas de computador e da criação audiovisual. Como fio condutor das experiências é ressaltada a subversão - tanto no formato de expressão quanto na possibilidade de criação e adequação de ferramentas digitais, destacando-se a importância do modelo de licenciamento do software livre. Os campos de expressão escolhidos foram o vídeo ao vivo (remix) e a criação e uso de software interativo, em diálogo com experiências brasileiras de arte aberta e de processo como obra.

Palavras-chave: arte-educação, cinema, software livre, programação

\section{Abstract}

This article shows a study about the use of open artworks on art-education practices, with focus on qualification processes and interdisciplinary colaboration. The experiences discussed here aim towards a path of empowerment by computer software development / modification and by audiovisual creation practices. As the conducting thread of the experience is the subversion - both on the expression format and on the possibility of the creation of digital production tools, pointing out the importance of the open source software format. The chosen expression fields were live video (remix) and the creation and use of interactive software, in dialogue with Brazilian experiences of open artworks and processes as works of art.

Keywords: art education, cinema, open source software, pogramming 


\section{0 cinema ao vivo como meio de expressão artística}

Este estudo tenta encontrar uma relação entre a prática artística e a transmissão de conhecimentos da área de criação em cinema digital ao vivo e o software interativo, vistos em sintonia, como obras abertas. A prática de cinema ao vivo é entendida como o processo de apresentação de conteúdo audiovisual para uma audiência, simultaneamente à criação. $\mathrm{O}$ vídeo foi escolhido como suporte para a criação por sua natureza multifacetada. "Ao contrário de outras formas expressivas, o vídeo apresenta-se quase sempre de forma múltipla, variável, instável, complexa, ocorrendo numa variedade infinita de manifestações. Ele pode estar presente em esculturas, instalações multimídia, ambientes, performances, intervenções urbanas (...)" (DUBOIS, 2004:13). A escolha de um método de criação que tem em seu cerne a questão da montagem (edição) aproxima o fazer artístico das práticas contemporâneas de captação e o compartilhamento eletrônico de imagens. Outro traço essencial para a compreensão dos processos de criação de arte nos tempos atuais é a interatividade. "Ao se colocar como ferramenta alimentadora do insight criativo, a interatividade é um procedimento que, potencialmente, assegura uma modificação substancial na relação entre artista, espectador e objeto criado, por permitir a instauração de processos de criação coletivos. (...) Os papéis (emissor / receptor) invertem-se mutuamente, tornando possível processos de co-criações" (PLAZA, 1998:105). Não somente pela amplitude do seu leque de utilizações práticas, mas também pela sua capacidade de servir de elo entre fazeres, como ressalta Christine Mello, "o vídeo passa a ser compreendido como um procedimento de interligação midiática e a ser valorizado em seu caráter de interface, como uma rede de conexões entre as práticas artísticas" (MELLO, 2008:36).

A imersão e a interatividade atuam com papéis importantes no processo de arte-educação. "O desenvolvimento intelectual significa um progresso gradual do conhecimento operativo sobre o figurativo; é o aspecto operativo que, construindo ou reconstruindo as coisas em pensamento, permite a apreensão da significação do objeto. Assim, a aprendizagem passa a ser considerada como algo pessoal, decorrente da ação do sujeito sobre os conteúdos" (CASTANHO, 2005:92).

O cinema ao vivo proporciona diálogos em áreas de discussão muito importantes para a arte contemporânea, tais como o tempo e a construção de narrativas multimídia, a apropriação e a interatividade. Neste trabalho, compreende-se o cinema ao vivo como o conjunto de práticas relativas à montagem (edição) de filmes, com apresentação simultânea à criação. "O trabalho ao ser apresentado ao público deixa de ser uma obra acabada, encerrada em si mesma, para se tornar uma obra participativa, em processo, inacabada, que necessita do outro para completar-lhe os sentidos." (MELLO, 2008:170) Trata-se, como preconizou Hélio Oiticica, da saída da arte do plano pictórico e escultórico para o plano da ação artística. O potencial da coautoria se concretiza não só na capacidade de modificação do software, mas na experiência do remix, uma recombinação de conte- 
údos e formatos. O processo permite uma capacitação para comunicação de conceitos e narrativas providos da força performática e dos desafios específicos do improviso, do caos e das conexões inesperadas. Observa-se aqui um ponto chave: o contraste com o sistema de ensino por meio de cópias e versões de desenhos e pinturas. O processo de programação/modificação de software e de criação de obras por meio da improvisação culmina para a valorização da síntese, tanto no sentido educacional da aprendizagem, como postulado por Lev Vygotsky, quanto no sentido cinematográfico, como posto por Sergei Einsenstein. Ambas as concepções de síntese entendem o produto final como algo totalmente diferente do que a soma ou justaposição dos seus elementos constituintes.

A questão da apropriação de imagens, que acontece com frequência nos processos de remix, agrega uma perspectiva subversiva à experiência, reforçando a questão da crítica aos formatos estabelecidos (formatos de software, formatos de narrativas, formatos legais de direitos autorais). Só a antropofagia nos une - Oswald de Andrade.

\section{Evolução de uma obra aberta (o software Quase-Cinema)}

O Quase-Cinema é um programa de computador para experiências nos campos de narrativa, composição e montagem cinematográficas ${ }^{3}$. O software permite a criação de performances de vídeo ao vivo, utilizando como matéria-prima o banco de imagens do artista (vídeos e imagens estáticas), texto e imagens de câmera de vídeo (webcam ou câmeras profissionais). O performer pode ajustar parâmetros de ritmo (medido por batidas por minuto) para coordenar a visibilidade, os efeitos de cor, a edição e a composição de camadas de vídeo, a fim de criar narrativas temporais ou composições visuais abstratas ${ }^{4}$.

A ideia para criação de um software de performance com vídeo ao vivo nasceu de uma necessidade de expressão desvinculada dos processos já engessados pelos softwares de produção audiovisual disponíveis no mercado. Previ que, munido de uma obra passível de modificações, poderia desenvolver trabalhos expressivos cada vez mais emancipados do um padrão estético vigente, imposto por limites técnicos aplicados a metodologias de trabalho dos programas de criação digital. Optei por criar um software capaz de operar em um suporte novo dentro da história do cinema e das artes performáticas: o audiovisual como performance improvisada.

O programa Quase-Cinema nasceu da minha necessidade expressiva no campo da imagem em movimento, mas evoluiu para uma ferramenta mais abrangente, fazendo

\footnotetext{
3 www.quasecinema.org

4 Registros das performances de videoarte realizadas pelo autor, com o software Quase-Cinema, podem ser vistos na página $<$ www.quasecinema.org/portfolio.html $>$.
} 
interseções com outras expressões artísticas além do cinema experimental, tal como a pintura gestual e o body-art. Desde a realização dos primeiros protótipos do programa, observei a potencialidade criativa do processo de ter acesso a um software "vivo". O conceito de programa vivo é evidenciado no ciclo de desenvolvimento do software, que é intimamente ligado aos processos de criação artística que utilizam o software. O ciclo inclui as seguintes etapas: a ideia para determinada expressão artística, a programação da função no software, o uso do software e a análise do uso - vislumbrando possíveis melhorias. "A máquina performa, no sentido artístico do termo, quando se deixa arrebatar, isto é, quando é dobrada em sua positividade técnica” (MEDEIROS, 2002:11).

O nome Quase-Cinema é uma homenagem ao artista plástico Hélio Oiticica e ao cineasta Neville d'Almeida, que assim também batizaram seus projetos audiovisuais transgressores. A relação principal com a obra de Hélio Oiticica ocorre no plano de transformação do espectador em protagonista, e do artista em propositor e "motivador para a criação" (BASUALDO, 2007). Também podemos traçar um paralelo com o cinema novo, de Glauber Rocha, só que agora, ao invés de uma câmera na mão, temos uma ilha de edição sob a ponta dos dedos.

A figura 1 mostra a interface da primeira versão funcional do software (0.1). A coluna de imagens na esquerda indica os clips (pedaços de filmes) disponíveis no disco de armazenamento do computador do usuário. A linha horizontal mostra 8 camadas de imagens para composição, que podem ser controladas individualmente. No centro da interface encontramos os controles de cada camada de clips: velocidade, tipo de mesclagem (blend), tamanho, posição e cores. O controle de cores permite a vinculação de cores diferentes aos tons claros e escuros das imagens originais, criando efeitos do tipo duotone, originalmente utilizados em artes gráficas (impressão com duas tintas). A área inferior direita contém os clips selecionados para acesso rápido, com uso do mouse ou atalhos de teclado. O nome VJ Xorume, visível também na interface, refere-se à persona artística adotada pelo autor para realização de performances de vídeo ao vivo. A referência é ao termo chorume, um resíduo do lixo urbano, aqui utilizado como metáfora de reciclagem de material audiovisual.

Desde o início do projeto, o programa aderiu ao formato de software livre. Entende-se como software livre um programa de computador que garanta determinados direitos ao usuário, entre eles os direitos de distribuição, estudo e adaptação. Essa foi uma escolha de postura, aqui nem subserviente (às potências tecnológicas mundiais) nem nacionalista, uma vez que vários componentes dos processos de criação e de utilização de mídias digitais ocorrem em equipamentos de tecnologia importada (câmeras, computadores, sistemas operacionais). Observou-se, sim, uma especificidade brasileira: a tendência, inclusive governamental, de uso do software livre, graças a seu potencial de emancipação tecnológica e seus baixos custos de distribuição e implantação. 


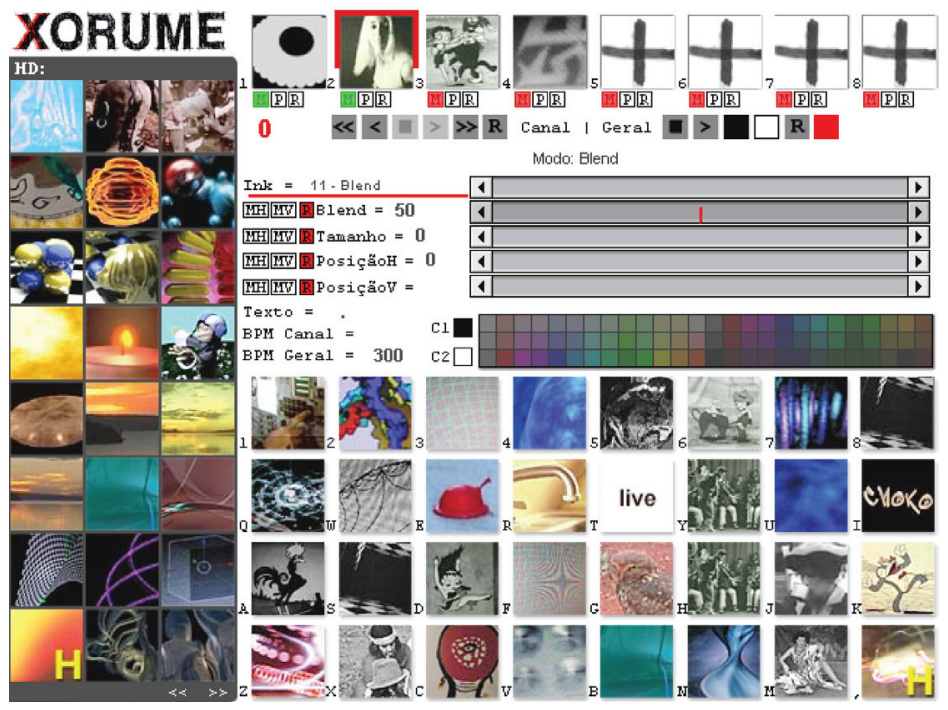

Figura 1.

Primeiro protótipo

operacional do software

Quase-Cinema (2005).

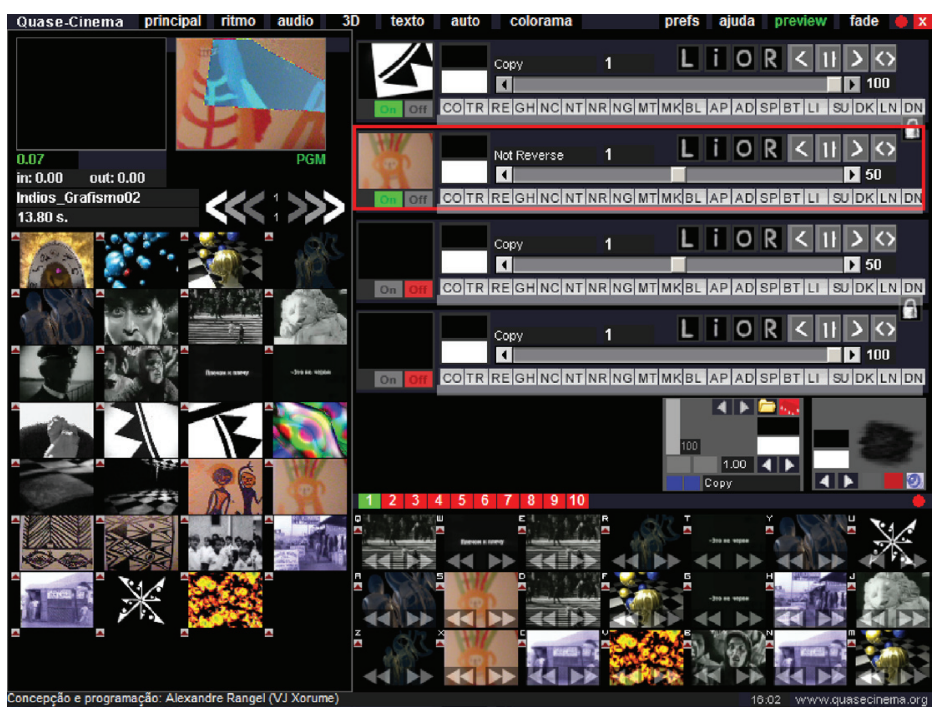

Figura 2.

Quase-Cinema versão 1 (2006).

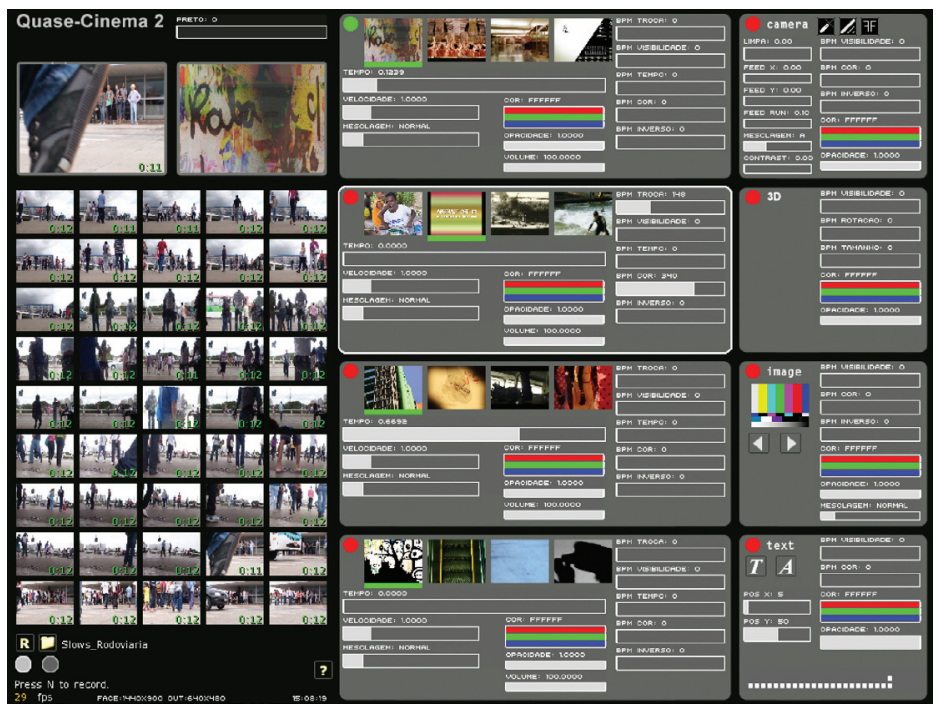

Figura 3.

Quase-Cinema versão 2 (2009). 
A primeira encarnação/materialização do software disponibilizada ao público (Figura 2) foi fruto de meu projeto final de graduação em artes plásticas pelo Instituto de Artes da Universidade de Brasília (IdA / UnB), sob a orientação do Prof. Dr. Elyeser Szturm.

Cada versão do Quase-Cinema possui capacidades exclusivas. Ou seja, as versões do programa não são necessariamente evoluções, mas sim mutações. Como uma das funções presentes somente na versão 1, podemos citar a capacidade de analisar o áudio ambiente para controlar parâmetros de uma camada de vídeo. Pode-se, por exemplo, vincular a transparência de um vídeo ao volume das frequências agudas (ou graves) do som do ambiente da performance. Outra peculiaridade dessa versão é o grande número de possibilidades de mesclagem entre as camadas de vídeo - vinte possibilidades, tais como clarear, escurecer, inverter...

A interface desta versão 1 foi organizada tendo como base quatro camadas de vídeo, uma área de pré-visualização de clips e dez bancos de clips para organização da performance e acesso rápido ao material audiovisual. $O$ foco da criação da interface do programa tem sido posto na sua facilidade de uso, tanto na questão do aprendizado inicial como na da facilidade de uso, por usuários mais experientes, durante performances ao vivo.

A versão inicial foi desenvolvida com a linguagem de programação de multimídia Director/Lingo ${ }^{5}$. As versões seguintes foram desenvolvidas, respectivamente, com as linguagens openFrameworks $/ \mathrm{C}++^{6}$ e Processing $/ \mathrm{Java}^{7}$. As mudanças de sistema de programação refletiram preocupações de longevidade do programa, performance e facilidade de programação, manutenção e colaboração. No formato atual de desenvolvimento (utilizando openFrameworks e Processing), a transparência e a abertura à colaboração externa são potencializadas, por estarmos desenvolvendo software livre utilizando software livre! Vale dizer que o Quase-Cinema funciona em sistemas operacionais livres (do tipo Linux) e também em sistemas mais difundidos (Windows e Mac OS X). Sempre saliento a adequação de tais ferramentas para utilização por artista / realizadores sem formação formal em programação de computadores, como é o meu caso: bacharel em artes plásticas e programador autodidata.

A versão 2 do programa (Figura 3) foi fruto da Bolsa de Estímulo à Criação Artística, da Fundação Nacional das Artes (Funarte / Ministério da Cultura), com a qual

6 http://www.openframeworks.cc

7 http://www.processing.org 
o projeto foi contemplado no ano de 2009. A bolsa permitiu que uma nova versão do software fosse criada por mim, em um período de seis meses. A versão 2 teve, como novidade principal, o controle de parâmetros das camadas de vídeo por meio de ajuste de BPM (batidas por minuto) durante a performance. Isso possibilita o trabalho direto com o ritmo da montagem (edição), criando uma amarração temporal do conteúdo visual ao conteúdo sonoro das apresentações. Também programei a função de integração de imagens ao vivo, por meio de webcam ou câmeras profissionais tipo DV (com conexão tipo Firewire).

\section{Evoluções individuais}

O software Quase-Cinema foi utilizado em várias oficinas de produção de vídeo artístico, como destacado nos próximos parágrafos. Como um projeto continuado, o objeto (software) recebeu críticas e sugestões que resultaram em sua contínua modificação, para atender a uma série de demandas criativas. Os participantes das oficinas são confrontados com a questão de que estão manipulando um sistema (software) que foi criado por uma pessoa (artista) dotada de determinados objetivos. E o mais importante é que esse sistema pode ser estudado, alterado e subvertido de acordo com as necessidades e ideias de expressão do usuário.

Dentro da proposta de obra aberta, o software é apresentado como a abertura de uma caixa-preta, evidencializando um processo de emancipação de limites técnicos tanto do artista como do público (aqui agindo como colaborador do projeto). Ocorre então uma desmistificação do ato de criação de uma peça de software. Uma vez tratadas as ideias decorrentes das discussões teóricas e técnicas das oficinas e exposições, dá-se início a um processo de retroalimentação do projeto, por meio de demandas dos usuários do programa. Os participantes com maior conhecimento técnico têm suas dúvidas esclarecidas, enquanto as pessoas que têm "somente" as ideias podem ver tais funções sendo esboçadas/programadas por outros participantes ou pelo programador principal. Ambas as partes do grupo são encorajadas a continuar as suas pesquisas e a colaboração em torno da criação de software criativo.

Um dos exemplos de modificações ocorridas foi a adição da capacidade de gravação das performances de vídeo, que transformou o sistema em um editor de peças finalizadas - em contraste com apresentações somente efêmeras. Muitas vezes, a linha de eventos que culmina em novas funcionalidades do software desenrola-se rapidamente, vide o exemplo da pintura com luz apresentado a seguir. Observo que a imediaticidade ideia/realização técnica só se torna possível com o uso de sistemas de software aberto (livre). 


\section{Pintura com luz - ao vivo}

A pintura com luz tradicional é o processo de sensibilização de filme fotográfico ou sensores de câmeras digitais com uso de luzes controladas (como pincéis). As fontes luminosas podem ser lanternas, fósforos, lasers, flashs fotográficos, etc. Seja com câmeras fotográficas analógicas ou digitais, o processo necessitava de uma exposição prolongada do fotograma para captar os traços de luz.

A partir da experiência de uma oficina artística do Quase-Cinema realizada no evento "Liquid Borderlands", ocorrido em Aalborg, na Dinamarca, em 2009 (Figura 4), empenheime então em criar um processo que viabilizasse a realização de pinturas com luz com vídeo (ao vivo), ao invés do processo com fotografia. Isso permitiria a observação dos traços enquanto eles eram desenhados, e não quando a fotografia estivesse disponível. Programei o efeito durante a semana de realização da oficina. Essa capacidade foi adicionada ao Quase-Cinema 2 como uma adequação aos afazeres e demandas do grupo de participantes da oficina. O encontro permitiu a realização de performances e oficinas, onde a tônica foi o compartilhamento de informações e a colaboração entre técnicos em eletrônica e artistas (com atuação em arte eletrônica e intervenções urbanas).

A efetivação do sistema de pintura com luz visualizável - e controlável - por meio do vídeo permitiu um diálogo da performance de VJ com as artes plásticas e a pintura gestual. O sistema vai um passo além, no sentido da transposição da pintura de abstração gestual para o vídeo, disponibilizando um controle do escorrimento (smearing) dos traços luminosos. Esta fusão atualiza as duas linguagens, enriquecendo a experiência como um todo, onde a multidisciplinaridade das capacidades expressivas (desenho, videografismo, programação) ganha um tônus de protagonismo.

O desdobramento seguinte utilizando o sistema de pintura com luz foi a criação da performance "Éon9" (Figura 5), apresentada como um ambiente sensorial interativo na galeria "Fortress to Solitude", em Nova York, em 2010. Considerei essa obra como a exploração com vídeo de uma nova técnica: "gravuras de luz". Se a pintura com luz permite desenhar de acordo com a movimentação de um ponto de luz (como um pincel), a gravura de luz procura fazer um registro de luminosidade a partir de fotogramas completos de vídeo. Daí a metáfora da gravura, já que cada quadro (frame) do vídeo se comportaria como uma matriz de gravação. A performance mesclou a pintura com luz, feita pelo artista ao vivo, usando uma lanterna, com a técnica de gravura com luz, usando vídeos feitos a partir de pinturas gestuais do artista Wagner Hermusche.

8 www.tossestreger.org/events/lib09-dokumentation-part1

9 Registro da performance "Éon": www.youtube.com/watch?v=uFLLuxSRFZ4 


\section{Expansão do suporte via video mapping}

Continuando uma busca de expansão do plano de expressão, presente em meu trabalho, procurei integrar ao Quase-Cinema a capacidade técnica de realizar projeções de vídeo mapeado (video mapping). O mapeamento de vídeo é uma técnica de projeção que possibilita a expansão do suporte das imagens, permitindo uma fuga do quadro / tela de projeção. Por meio da manipulação de pontos geométricos, programas de computador podem dimensionar e distorcer planos de projeção a fim de criar encaixes com determinados objetos, esculturas, ou obras arquitetônicas.

O primeiro desafio a partir do conceito técnico de mapeamento de vídeo foi uma oficina no evento "VideoAtaq10", no Centro Cultural Parque das Ruínas, no Rio de Janeiro, em 2010. Abordei a oficina como possibilidade e incentivo para a criação da nova função. Trabalhei com o grupo as possibilidades de funcionamento e interface com o usuário do programa. Ao final da oficina, aconteceram performances de vídeo ao vivo com projeção na fachada do Parque das Ruínas, local de encontro da boemia carioca na primeira metade do século XX.

A oportunidade seguinte para exploração, apresentação e desenvolvimento da ferramenta de mapeamento de vídeo foi o evento "Jornada Brasileira de Imagens ao Vivo - Entre a partitura e o improviso ${ }^{11 "}$, ocorrido em Fortaleza, em 2010, no Centro Cultural Banco do Nordeste (Figura 6). O mapeamento funciona, neste contexto, como uma ferramenta para expansão do suporte imagético; a subversão acontece quebrando paredes e trazendo a arte para o lado de fora da galeria, interferindo agora no circuito de exibição de arte.

\section{Adaptação para uso em galerias de arte}

Exemplificando a possibilidade de uso e adaptação do Quase-Cinema por iniciativas educacionais, cito o convite que recebi para contribuir com a tese de doutorado "VJ-Edu: vídeo jockey educativo em software interativo para o visitante de uma exposição de arte”. Convidado pelo Dr. Júlio Caetano Costa, realizamos uma imersão criativa de uma semana de duração em Nova York, ponto de encontro entre a minha residência em Brasília e Montreal, no Canadá, onde o pesquisador realizava seu trabalho. A proposta foi fazermos uma versão do Quase-Cinema adaptada para uso em instituições museológicas, como ferramenta de auxílio à equipe de monitoria de exposições de arte. O software adaptado permite uma utilização direcionada à compreensão de um universo maior de obras do artista realizando a mostra, disponibilizando registros de outras

10 www.videoataq.com.br

11 www.cinemaaovivo.wordpress.com/os-trabalhos 
obras, entrevistas e material gráfico complementar à exposição. O objetivo da colocação do software neste contexto é a expansão da experiência no ambiente expositivo, criando novos contextos a partir de recombinações (remix) e olhares únicos sobre o material disponibilizado. A versão VJ-Edu também permite o seu uso por meio de dispositivos do tipo smartphone com telas sensíveis ao toque.

\section{Feijoada como o remix primordial}

Desde 2011, venho desenvolvendo uma nova versão do programa Quase-Cinema, sem que a versão anterior se torne obsoleta, já que as versões possuem funcionalidades diferentes. Uma das principais características desta etapa mais recente do projeto contempla uma modificação no formato de criação/distribuição. O software foi disponibilizado já no início da sua programação, ao invés de no final, como nas versões 1 e 2 . Acredito que dessa forma o projeto se apresente mais susceptível de receber contribuições, visto que ainda se encontra no estágio inicial de desenvolvimento. Por meio do sistema/ site de compartilhamento de programação GitHub ${ }^{12}$, os colaboradores e interessados no projeto podem ver, passo a passo, todas as decisões tomadas pelo programador principal durante a construção do programa. Comparo esse sistema de construção transparente com uma "pintura aberta", onde cada uma das pinceladas do artista pode ser observada e avaliada individualmente e cronologicamente, sendo passível de comentários e modificações.

O nome da mais nova versão do software é Quase-Cinema Feijoada Remix, ressaltando ainda mais a sua brasilidade e prevendo tornar-se um caldeirão de novas possibilidades criativas. As principais características desta obra em progresso são a possibilidade de uso de controladores externos tipo Midi (permitindo uma maior mobilidade cênica do performer), a integração de mapeamento de vídeos em áreas com ângulos retos ou formas curvilíneas e uma interface mais aberta a expansões. O lançamento dessa versão aconteceu em uma oficina durante o "Festival Internacional Cultura Digital.br 13", realizado em 2011 no Museu de Arte Moderna do Rio de Janeiro, sinalizando a viabilidade do desenvolvimento continuado do projeto Quase-Cinema.

Os exemplos reunidos de obras e desenvolvimentos de software apresentados sustentam a ideia de um formato de arte-educação emancipadora, onde os participantes do processo (corpos discente e docente) são incentivados a buscar as suas próprias soluções e processos criativos.

12 https://github.com/AlexandreRangel/QuaseCinemaFeijoada

13 www.culturadigital.org.br 


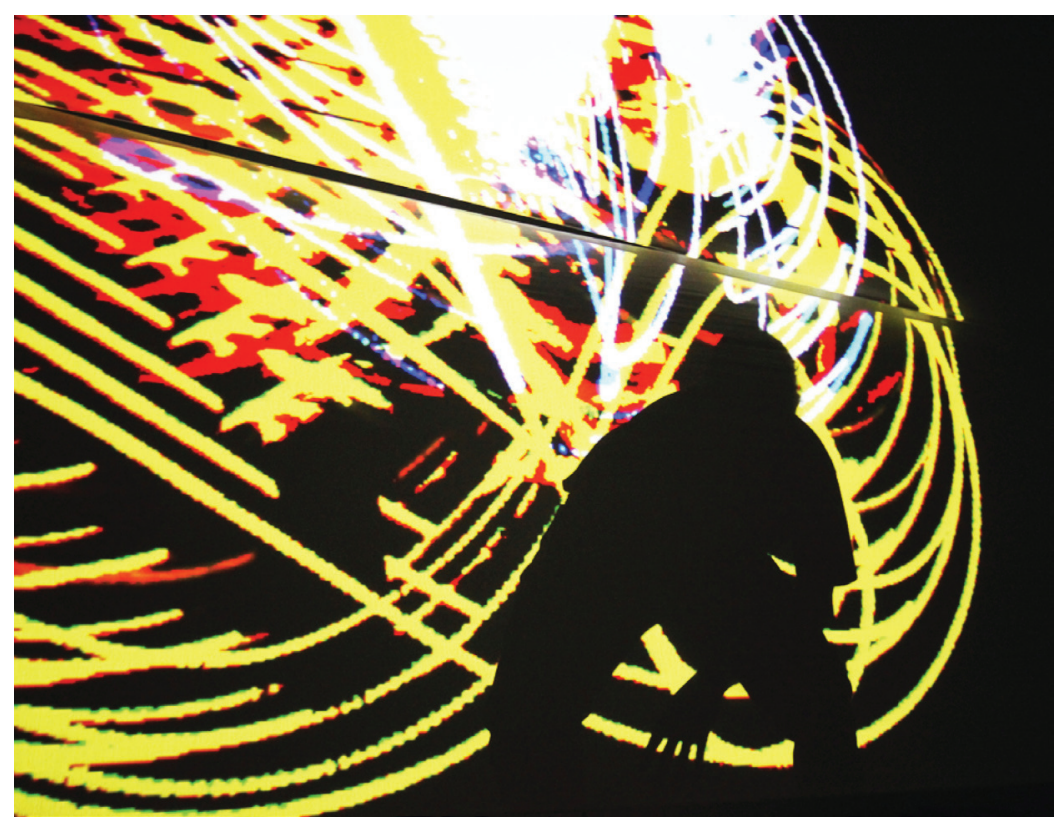

Figura 4.

Alexandre Rangel em performance com pintura com luz.

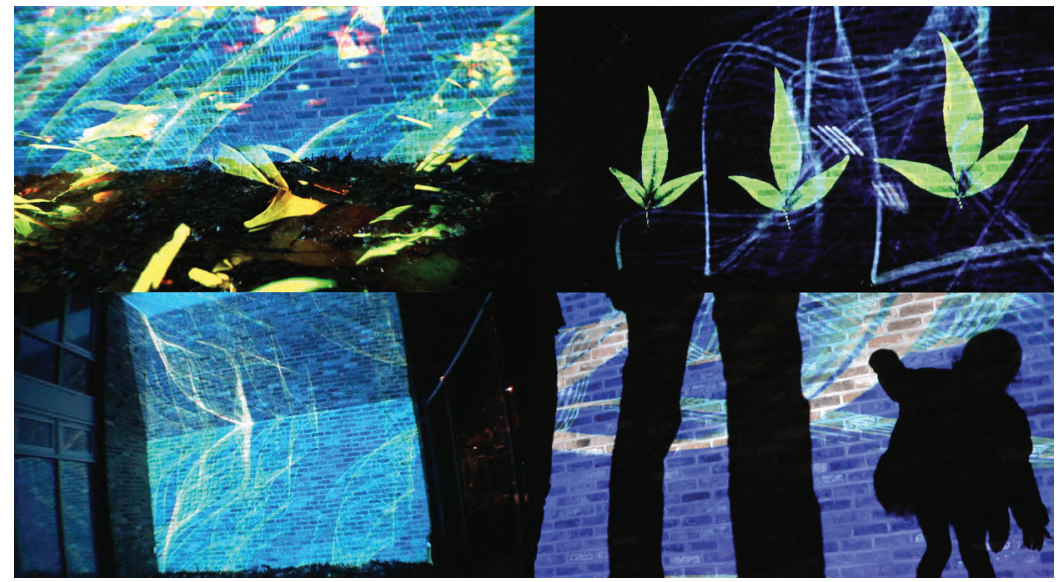

Figura 5.

Performance "Éon", de Alexandre Rangel e Wagner Hermusche (2010).

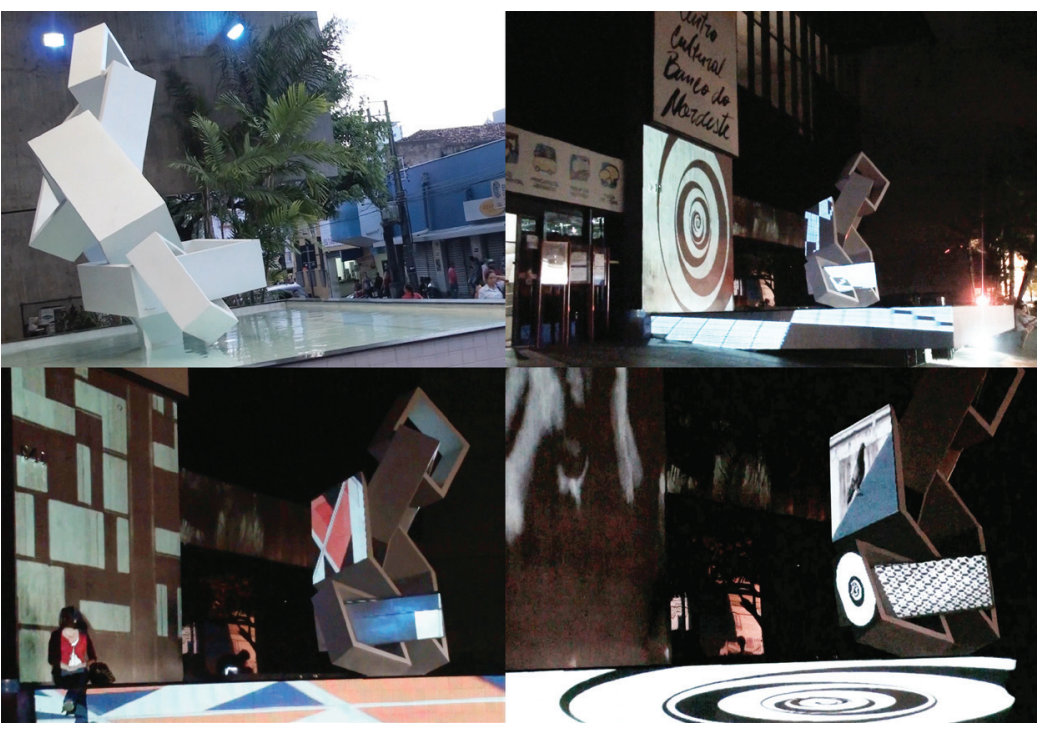

Figura 6.

Mapeamento de vídeo na escultura "Quadrado", do artista Sérvulo Esmeraldo. 


\section{Fontes das imagens}

Figura 1 - Interface do protótipo 0.1 do Quase-Cinema. Fonte: autor.

Figura 2 - Interface do Quase-Cinema versão 1. Fonte: autor.

Figura 3 - Interface do Quase-Cinema versão 2. Fonte: autor.

Figura 4 - Alexandre Rangel em performance de pintura com luz. Foto: Simon Andersen.

Figura 5 - Quadros de registro em vídeo da performance “Éon”. Fonte: autor.

Figura 6 - Mapeamento de vídeo em escultura de Sérvulo Esmeraldo, em Fortaleza. Quadros de registro em vídeo. Fonte: autor.

\section{Referências bibliográficas}

BASUALDO, Carlos (org.). Tropicália: uma revolução na cultura brasileira. São Paulo: Cosac Naify, 2007.

DUBOIS, Philippe. Cinema, vídeo, Godard. São Paulo: Cosac Naif, 2004.

CASTANHO, Maria Eugênia L. M. Função educacional da arte. Revista Educação Temática Digital - Faculdade de Educação da Universidade Estadual de Campinas (FE/ UNICAMP), 2005. vol. 6, p. 85-98.

COSTA, Júlio Caetano. VJ-Edu: vídeo jockey educativo em software interativo para o visitante de uma exposição de arte. Tese (Doutorado). Universidade Federal do Rio Grande do Sul, Centro de Estudos Interdisciplinares em Novas Tecnologias da Educação, Programa de Pós-Graduação em Informática na Educação. Porto Alegre, 2011. Disponível em:

< www.lume.ufrgs.br/handle/10183/39668 > . Acesso em: 29 abril 2012.

EISENSTEIN, Sergei. A forma do filme. Jorge Zahar Editor, 2002.

EISENSTEIN, Sergei. O sentido do filme. Jorge Zahar Editor, 2002. 
MEDEIROS, Maria Beatriz de (Org.). Arte e tecnologia na cultura contemporânea. Brasília: Dupligráfica Editora Ltda, 2002.

MELLO, Christine. Extremidades do vídeo. São Paulo: Editora Senac, 2008.

PLAZA, Julio; TAVARES, Monica. Processos criativos com os meios eletrônicos: poéticas digitais. São Paulo: Editora Hucitec, 1998. 